\title{
Experimental study of carbon nanotubes in high viscosity lubricants
}

Carbon nanotubes (CNTS) beneficial tribological properties were reported in numerous studies performed mostly in idealized tribometer conditions, previously described full engine tests confirmed that CNTs added to the lubricating oil reduced friction significantly. Apparently the engine application requires low CNT concentration in oil, otherwise when increasing the CNT concentration beyond a certain level oil viscosity increases, rapidly forming a greasy substance not suitable for engine lubrication. In this paper we report a study of tribological properties of such a high viscosity lubricant performed in Amsler tribometer in comparison to high quality commercially available lithium grease. The CNT based high viscosity lubricant in its current formulation turned out as not reliable for general application due to its low adhesion to the metal surface. In contrary to some samples made of a polymer widely used in industry as a friction component, we observed wear reduction reaching nearly $50 \%$ when replacing the best suitable lithium grease by a CNT based lubricant. This effect was first observed after 30 min into a friction test, suggesting a CNT related mechanism of anti-wear protection which still need to be explained.

Key words: carbon nanotubes, friction, grease

\section{Introduction}

Carbon Nanotubes (CNTs) 're-discovered' by Sumio Iijima in 1991 have been intensively studied in the recent years; their often-reported unique combination of excellent physicochemical properties is extremely beneficial for tribological performance [1-4]. Despite the promising preliminary laboratory test results presented in the literature the early attempts of CNTs commercialization were disappointing [5]. In our opinion there are two main aspects that must be addressed before attempting large-scale industrial application of CNTs in lubricants. These aspects are: the stability of CNTs dispersion, and understanding of the mechanisms of CNTs tribological effects. Our engine tests described previously $[6,7]$ lead to the conclusion, that only well dispersed CNTs contribute to any significant friction reduction. The same level of total engine friction reduction, reaching a notable value of about $5 \%$, was measured both for CNTs concentration in oil equal to $0.5 \%$ and in the case for concentration over ten times lower. In the first case only standard ultrasound homogenization was used, but a major improvement in the CNTs dispersion was achieved for the low CNT concentration using a simple and effective chemical methods. In [7] a smart solution was presented for constant CNT release into the lubricating oil, leading to a perfect dispersion and an unprecedented friction reduction of up to $16 \%$. On the other hand our early attempts to exploit the friction reducing ability of CNTs by increasing their concentration in oil seemed to fail because at concentration as high as $1 \%$ the oil was converted during engine operation into a greasy substance that became too viscous to pump [6]. Disappointing engine test result turned into a new fascinating project where the high viscosity lubricant taken directly from the engine (labeled S0 in experiments described in this paper) was tested outside the engine and compared with top quality grease. A set of relevant tribometer test results was presented in this paper in an effort to achieve a detailed understanding of the physical phenomena related to the CNT effects in lubricants. Depending on the actual local friction conditions CNTs may reveal various functional mechanisms occurring simultaneously during the friction process [8-10].

In this study we used Amsler tribometer with rotating steel ring, pushing against the samples made of cast iron, brass, aluminum and polymer, forming a friction pair lubricated with CNT based lubricants of various formulation and high quality commercially available grease as a reference sample. For our tests we used a polymer widely used as a material for friction components due to its low cost, good mechanical properties, low friction coefficient, and easy manufacturing. Until now the knowledge concerning manufacturing and tribological properties of CNT based high viscosity lubricants is marginal and partly incoherent $[11,12]$.

\section{Materials and methods}

\subsection{Lubricants}

High viscosity lubricants based on carbon nanotubes as thickener were tested in a tribometer and compared to standard lithium grease as commercially available top quality product based on PAO synthetic oil thickened with lithium soap (S1). All lubricants tested in the trials described below can be found in the Table 1.

Table 1 Formulation of lubricants

\begin{tabular}{|l|c|c|}
\hline Lubricant & OIL & Thickener \\
\hline S0 & Mobil 1 0W/40 & $1 \%$ MWCNTs \\
\hline S1 & Synthetic, PAO + additives & Lithium complex \\
\hline S2 & Synthetic, PAO + additives & $\begin{array}{c}\text { Lithium complex } \\
0.5 \% \text { MWCNTs short }\end{array}$ \\
\hline S4 & Orlen Platinum 5W/30 & $3 \%$ MWCNTs short \\
\hline S5 & VW Oil 5W/30 & $2 \%$ MWCNTs short $^{1}$ \\
\hline S6 & Castrol RS $10 \mathrm{~W} / 60$ & $1 \%$ MWCNTs short $^{1}$ \\
& & $0.2 \%$ MWCNTs long ${ }^{2}$ \\
\multicolumn{2}{|c|}{} & $0.2 \%$ Graphene $^{2}$ \\
\hline \multicolumn{2}{|c|}{ outer diameter $9.5 \mathrm{~nm}$, length $1.5 \mu \mathrm{m}$} \\
${ }^{2}$ outer diameter $>50 \mathrm{~nm}$, length $10 \ldots 20 \mu \mathrm{m}$ \\
\hline
\end{tabular}

The S0 lubricant was produced accidentally in engine tests described in [6], but the lubricants S4, S5, S6 were obtained in 
ultrasound disintegrator. Lubricant S2 is standard S1 grease mixed with CNTs.

\subsection{Tribometer}

The friction tests were carried out with the use of equipment located in the Sustainability and Wear Laboratory at the Poznan University of Technology (Institute of Machines and Motor Vehicles).

For comparative tests, the Amsler A-135 friction machine was used. The friction node consisted of a rotating cylindrical ring, against which a rectangular sample was pressed facing the friction surface. The rings in the tests has an outer diameter of $40 \mathrm{~mm}$ and a thickness of $10 \mathrm{~mm}$, and were made of hardened steel with a hardness of $60 \pm 2 \mathrm{HRC}$ on the friction surface. The samples were rectangular $15 \times 10 \times 5 \mathrm{~mm}$ elements made of various metal and polymer materials.

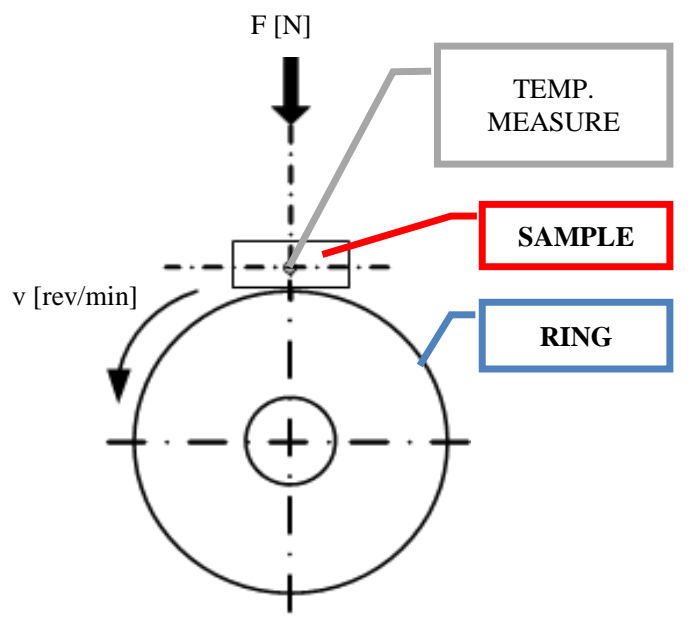

Fig. 1. Kinematics of Amsler Tribometer with tested sample pressed under controlled load against rotating ring

Before and after the tests, the tribometer performed surface profilograms of the samples and rings using a ZEISS contact profilometer equipped with heads with an inductive transducer and SAJD METROLOGIA software called SUFORM allowing the measurement and analysis of straightness and surface roughness deviations. The measurements were carried out using a measuring arm with diamond contact tip (without glider) in the shape of a pyramid with a rounded tip. The vertical range for measurements using the induction head was $\pm 200 \mu \mathrm{m}$. The speed of the measuring tip travel used during measurements was $0.1 \mathrm{~mm} / \mathrm{s}$ (the device's capabilities are $0.01 \mathrm{~mm} / \mathrm{s}$ to $1 \mathrm{~mm} / \mathrm{s}$ ). The measurements were made by setting a single segment size to be $\lambda_{c}=0.25 \mathrm{~mm}$, where the $L_{n}$ measuring section was $4 \mathrm{~mm}$. Cut-off filtration was used in the analysis of the surface roughness results.

After the friction tests the samples were once again used to produce four additional profiles for each sample. Three were done perpendicular to the friction groove and one profile was done along the groove at the point of the largest depth change. Having profilograms made across the groove, it was possible to determine the average groove depth for a given sample group, representing wear. Results were also scattered by specifying half-intervals of confidence for the average value at the significance level of 0.1 .

\section{Results and discussion}

\subsection{Preliminary tests for friction components made of various materials}

Preliminary tests were performed for the high viscosity lubricant taken directly from the engine oil sump (label S0). The main goal was to recognize the lubricating properties of the product for wide range of materials typically used as friction components. Aside from cast-iron we used aluminum, brass and polymer samples sliding on the steel ring of the Amsler tribometer (Fig. 2). In this trial the test time was reduced, down to $1 \mathrm{~min}$ for each sample, the speed and load were $200 \mathrm{~min}^{-1}$ and $1100 \mathrm{~N}$ respectively. For most sample materials the high viscosity lubricant S0 couldn't reach the lubricating performance of the high quality commercially available grease. As a result higher wear was measured on the samples, especially for aluminum (Fig. 2). This could be explained with low adhesion of the CNT based grease to the metal surface. Remarkably, better results were obtained for the tested polymer, a material widely used as friction component in technical application. Thus, in the following tests we focused on polymer friction components.

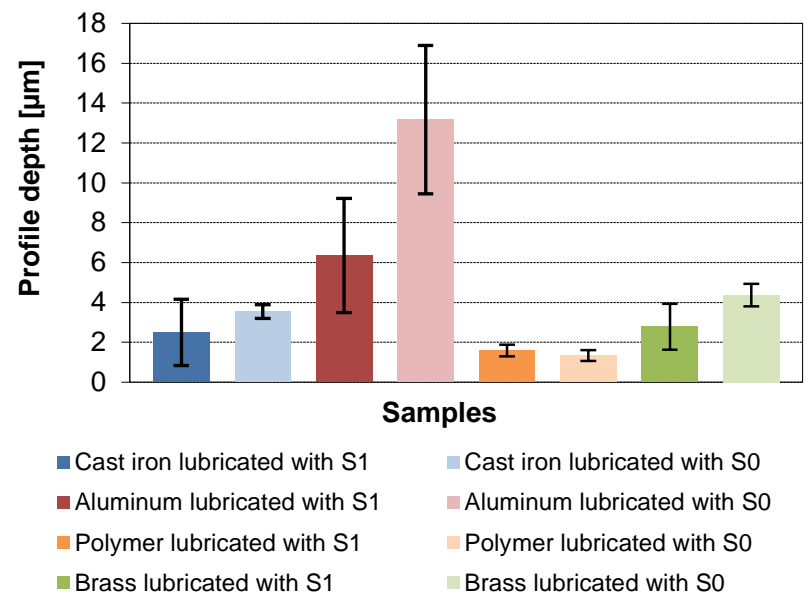

Fig. 2. Comparison of lubricants S0 vs. S1; wear measured after one minute friction tests on the surfaces of samples produced from different materials; mean values and confidence intervals for mean values at significance level of 0.1

\subsection{5-minute tests for polymer surface}

Three samples and rings were prepared for each of the lubricants tested. The lubricant was introduced by covering the friction surface of the sample and the ring with a given lubricant achieving a layer with a thickness of at least $2 \mathrm{~mm}$ before the friction test began, and then additionally covering the friction surfaces of just the rings during the friction tests at $6 \mathrm{~min}$ and $10 \mathrm{~min}$ in. The friction test duration was set at $15 \mathrm{~min}$. During the friction test, resistance to motion and temperature were measured using a thermocouple under the surface of the sample at a depth of about $3 \mathrm{~mm}$. Measurements were made at $50 \mathrm{~s}, 2 \mathrm{~min}, 5 \mathrm{~min}, 7 \mathrm{~min}, 10$ min, $13 \mathrm{~min}$ and $15 \mathrm{~min}$. During the 15 -minute test, the ring speed was $\mathrm{v}=228 \mathrm{rpm}$ and the load $\mathrm{F}=1200 \mathrm{~N}$. 
The friction test with the use of lubricant S1 had a clear impact on the reduction of the surface roughness, for the material of the tested plastic, which defined by parameter $\mathrm{Ra}$ reached an average value of $0.11 \pm 0.03 \mu \mathrm{m}$ (Fig. 3). When analyzing the result of surface roughness measurements, the presence of S5 lubricant had a clear influence on the increase of the tested material surface roughness, as seen by the increased average value of the Ra parameter. This takes place both in relation to the friction test involving the lubrication of this material with $\mathrm{S} 1$ and in relation to the surface roughness of the tested plastic at the beginning of the friction test. The value of Ra after a 15-minute friction test in this case can on average reach $0.33 \pm 0.05 \mu \mathrm{m}$.

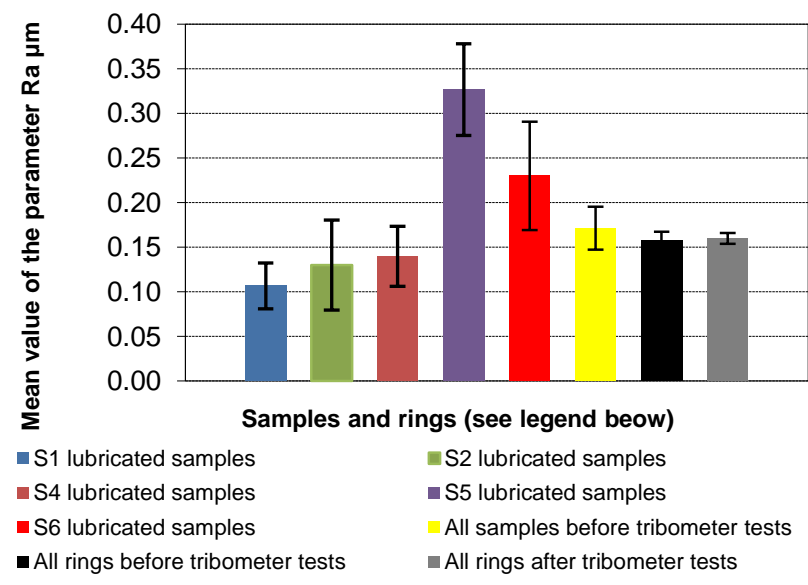

Fig. 3. Ra parameter for samples and rings before and after tests in the Amsler tribometer; mean values and confidence intervals for mean values at significance level of 0.1

The average Ra parameter values for rings before and after the friction process showed no differences. This may indicate the lack of impact of any of the tested lubricants on the wear of the steel spigot in the plain bearing when operating with the tested plastic in simulated friction conditions.

It should be noted that there are no differences in surface roughness (no difference in parameter $\mathrm{Ra}$ ) of the friction surface of the samples and rings prior to the friction tests, which minimized the friction test preparation, which is beneficial from the point of view of the test results.

The use of selected lubricants S2, S4 and S6 in the tested friction setup (in conditions determined by the experiment) did not affect the increase or decrease of surface roughness after the tests.

The results of the average $\mathrm{Ra}$ parameter values along with the result data spread also indicate no difference between the roughness on the friction surface of the tested material with the use of lubricants S5 and S6. Figure 4 shows the view of one of the samples lubricated with S6 grease. The friction surface indicates the presence of parallel scratches that may indicate abrasive wear (Fig. 4b).

The results of average groove depth value measurements of the surface roughness profiles (Fig. 5) being a measure of wear, indicate no differences in the wear level of surfaces lubricated using S2, S4 and S6. It should be emphasized, however, that the average values of wear indicate a greater wear of the tested material in the friction tests when using the previously mentioned three lubricants than in the case of $\mathrm{S} 1$.
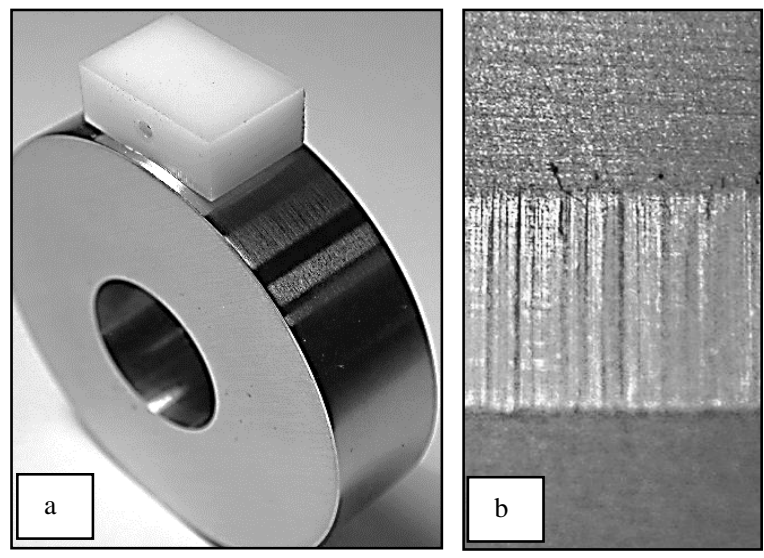

Fig. 4. Amsler tribometer: friction components (a) and scratches on the polymer sample after S6 lubricant test (b)

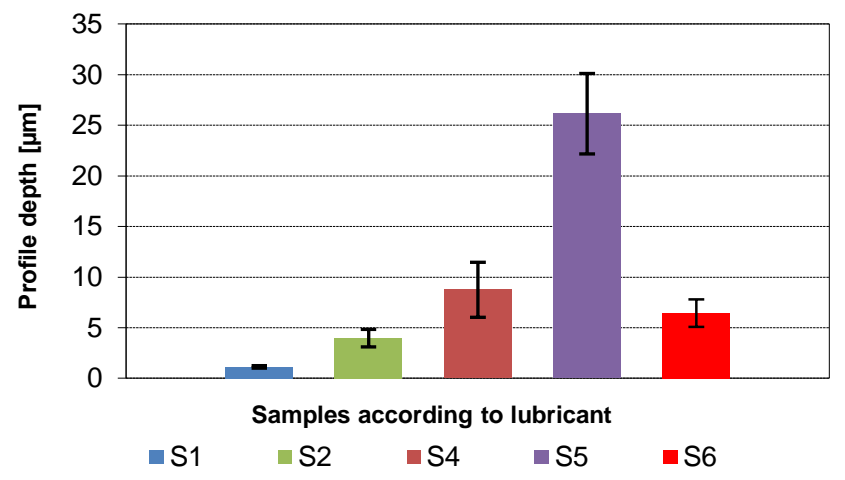

Fig. 5. Wear measured on the polymer samples after test performed for various lubricants; depth of the friction track profile; values and confidence intervals for mean values at significance level of 0.1

The wear results unambiguously indicate that the smallest wear in the simulated contact during sliding friction was observed when using lubrication with $\mathrm{S} 1$.

The use of S5 in the tests resulted in the highest values of sample wear in relation to the other lubricants tested (Fig. 5). The unfavorable lubricating effect of the S5 lubricant is further confirmed by the significant sample temperature increase as a result of the friction, Fig. 6.

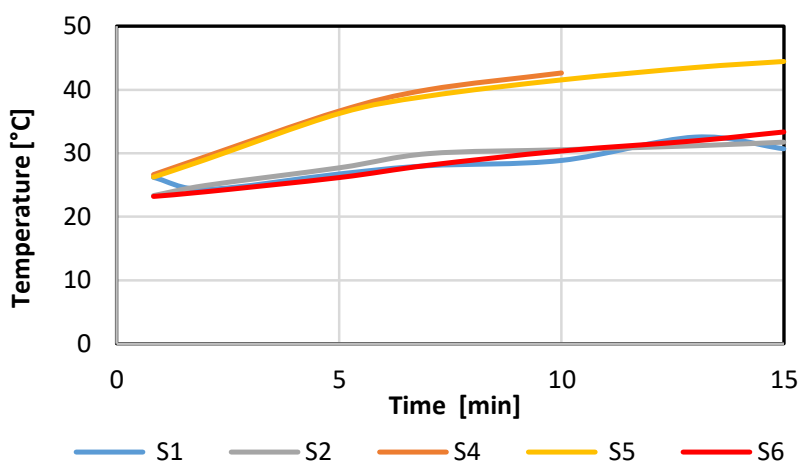

Fig. 6. Temperature in the sample material during friction test in tribometer; mean values for tested lubricants 


\subsection{0 minute tests for polymer surface}

For the polymer samples an additional test was performed to compare the best CNT based lubricant to the standard commercial one, with results shown in Fig. 7.

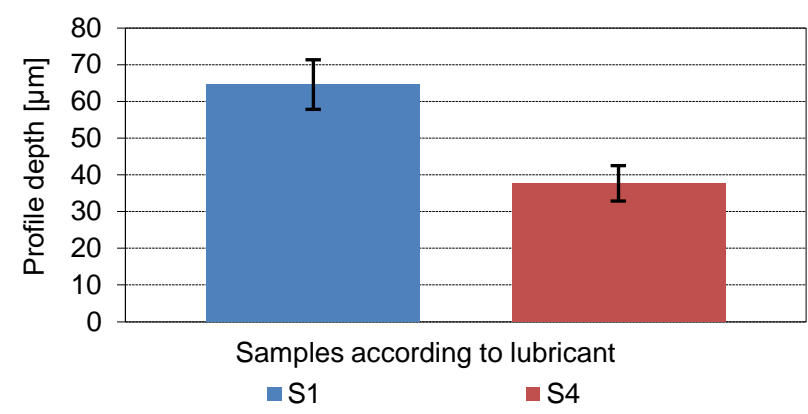

Fig. 7. Mean wear values measured as groove profile depth; comparison for S1 and S4 lubricant tested on polymer samples; mean values and confidence intervals for mean values at significance level of 0.1

Similarly to the 15-minutes test the speed of the ring was $\mathrm{v}=228 \mathrm{rpm}$, the load in Amsler tribometer was set to $\mathrm{F}=1200 \mathrm{~N}$, but the operating time was extended to 30 minutes. The S1 lubricant that previously provided the best results failed in this prolongated test, leading to an extremely high wear characterized by groove depth of over $64 \mathrm{mi}-$ crons. For the same friction conditions the CNT based lub- ricant lead to a groove no deeper than 38 microns. We hypothesize a CNT related mechanism of anti-wear protection which still needs to be explained.

\section{Summary}

The presented preliminary tests of high viscosity lubricant formulated by commercially available engine lubricating oil with the addition of CNTs allowed us to reveal a unique, strong interaction of CNTs and the polymer surface. For long-duration friction tests the wear observed on polymer sample surface lubricated by CNT based grease was nearly $50 \%$ smaller than for the reference high quality lithium complex grease. On the other hand, friction tests performed for the CNT based lubricant on metal samples failed due to low lubricant adhesion to metal surfaces.

For all tested surfaces we observed a strong impact of the CNT based lubricant formulation on the wear results, this justifies further experiments targeting the role of nanocarbon morphology in friction processes. In general the obtained results are necessary for better understanding of the CNTs role in the friction processes. Therefore extended studies of the CNTs based lubricants rheology and microscopic structure as well as a characterization of the wear grooves are necessary.

\section{Bibliography}

[1] ETTEFAGHI, E., AHMADI, H., RASHIDI, A. Preparation and properties of oil-based nanofluid from multi-walled carbon nanotubes and engine oil as nano-lubricant. International Communications in Heat and Mass Transfer. 2013, 46, 142-147.

[2] ERDEMIR, A., RAMIREZ, G., ERYILMAZ, O.L. et al Carbon-based tribofilms from lubricating oils. Nature. 2016, 536, 67-71.

[3] MENG, Y, SU, F, CHEN, Y. Supercritical fluid synthesis and tribological applications of silver nanoparticle-decorated graphene in engine oil nanofluid. Sci. Rep. 2016, 6, 31246.

[4] ESWARAIAH, V., SANKARANARAYANAN, V., RAMAPRABHU, S. Graphene-based engine oil nanofluids for tribological applications. ACS Appl Mater Interfaces. 2011, 3, 4221-4227.

[5] De VOLDER, M.F.L., TAWFICK, S.H., BAUGHMAN, R.H., HART, A.J. Carbon nanotubes: present and future commercial applications. Science. 2013, 339.

[6] KAŁUŻNY, J. et al. Lubricating performance of carbon nanotubes in internal combustion engines - engine tests results for CNT enriched oil. IJAT. 2017, 18(6).

Jarosław Kałużny, DSc., DEng. - Faculty of

Transport Engineering, Poznan University of Technology.

e-mail: jaroslaw.kaluzny@put.poznan.pl

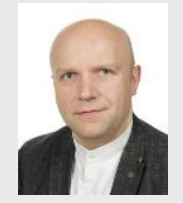

Aleksander Stepanenko, MEng. - Faculty of Transport Engineering, Poznan University of Technology.

e-mail: stepanenko@wp.pl.

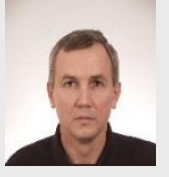

[7] KAŁUŻNY, J., MERKISZ, J., KEMPA, K. Friction reducing performance of carbon nanotubes covered pistons in internal combustion engines - engine test results. Combustion Engines. 2018, 172, 14-24.

[8] CHAVEAU, V., MAZUYER, D., DASSENOY, F., CAYER-BARRIOZ, J. In situ film-forming and frictionreduction mechanisms for carbon-nanotube dispersions in lubrication. Tribol Lett. 2012, 47, 467-480.

[9] HWANG, Y., LEE, C., CHOI, Y. et al. Effect of size and morphology of particles dispersed in nano-oil on friction performance between rotating discs. Journal of Mechanical Science and Technology. 2011, 25(11), 2853-2857.

[10] DAI, W. et al. Roles of nanoparticles in oil lubrication. Tribology International. 2016, 102, 88-98.

[11] HONG, H. et al. Carbon nanotube grease with enhanced thermal and electrical conductivities. J Nanopart Res. 2010, 12, 529-535.

[12] HONGTAO, L. et al. Tribological properties of carbon nanotubes grease. Industrial Lubrication and Tribology. 2014, 66(5), 579-583.

Grzegorz Kinal. DEng. - Faculty of Transport Engineering, Poznan University of Technology. e-mail: grzegorz.kinal@put.poznan.pl

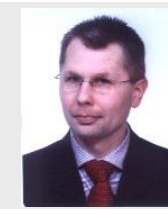

Prof. Jerzy Merkisz, DSc., DEng. - Faculty of Transport Engineering, Poznan University of Technology.

e-mail: jerzy.merkisz@put.poznan.pl

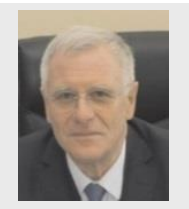

